\title{
Isomerization of $\alpha$-pinene over ion-exchanged natural zeolites
}

\author{
Fehime Özkan ${ }^{\mathrm{a}, *}$, Gönül Gündüz ${ }^{\mathrm{b}}$, Oguz Akpolat ${ }^{\mathrm{c}}$, Nurgun Beşün ${ }^{\mathrm{b}}$, Dmitry Yu. Murzin $^{\mathrm{d}}$ \\ ${ }^{a}$ Chemical Engineering Department, Izmir Institute of Technology, Gulbahce Koyu, 35437 Urla, Izmir, Turkey \\ ${ }^{\mathrm{b}}$ Department of Chemical Engineering, Ege University, Bornova, Izmir, Turkey \\ ${ }^{\mathrm{c}}$ Department of Bio. Engineering, Ege University, Bornova, Izmir, Turkey \\ ${ }^{\mathrm{d}}$ Laboratory of Industrial Chemistry, Process Chemistry Group, Abo Akademi University, Turku, Abo, Finland
}

\begin{abstract}
Catalysts prepared by ion exchange of clinoptilolite-based natural zeolite tuffs with $\mathrm{NH}_{4}^{+}, \mathrm{Ba}^{2+}$ and $\mathrm{Pb}^{2+}$ were investigated in the isomerization reaction of $\alpha$-pinene at atmospheric pressure under nitrogen flow. Activity and selectivity to mono-, bi- and tricyclic products were correlated with acidity strength.
\end{abstract}

(C) 2002 Elsevier Science B.V. All rights reserved.

Keywords: Isomerization; $\alpha$-Pinene; Clinoptilolite; Ion-exchange

\section{Introduction}

Isomerization of $\alpha$-pinene (1,6,6-trimethylbicyclo[3.1.1] hept-2-ene) over $\mathrm{TiO}_{2}$ catalyst is a conventional way of producing terpene products. Tricyclic products contain, besides camphene, which is an important intermediate in camphor synthesis, also tricyclene and small amounts of fenchenes and bornilene. In industrial conditions overall yield of these products is around $75-80 \%$. The reaction product mixture includes, besides several bi- and tricyclic terpenes, monocyclic compounds such as limonene, terpinenes and terpinolenes (Fig. 1). Isomerization of $\alpha$-pinene is generally carried out in the liquid phase at reflux temperature in the absence of water. Conventional titanium oxide catalysts are prepared by treating $\mathrm{TiO}_{2}$ with an acid to achieve a layer of titanic acid on oxide surface. Activity and selectivity is associated with the acidity of titanium catalysts. The reaction rate over $\mathrm{TiO}_{2}$ is rather low and industrial interest is in finding catalytic materials which possess much higher activity and selectivity.

Various types of catalysts prepared from titanium dioxide [1-6], clays [7-9], halloysite [10,11], natural zeolites [12-16], activated carbon [17], synthetic zeolites [18-29] and silica supported rare earth oxides [21] have been reported in the literature for the isomerization of $\alpha$-pinene. It is well known that the difference in acidity of the catalyst influences $\alpha$-pinene isomerization especially with respect to limonene. Besides camphene there is a growing interest in producing limonene or dipentene, as the most important terpene resins are derived from it.

\footnotetext{
* Corresponding author.
}

Acid strength of catalysts has an effect on selectivity ratio of bi- and tricyclic to monocyclic products. The activity and selectivity in $\alpha$-pinene isomerization over $\mathrm{X}$ and Y zeolites [20] were seen to be strongly influenced by both the number of framework and of non-framework aluminum atoms per unit cell. For high values of framework aluminum atoms extra-lattice aluminum species have a promoting effect on activity. Catalytic activity decreased with increase of these atoms in case of highly dealuminated samples. Selectivity behavior was explained by formation of camphene and bicyclic products on the Lewis sites of non-framework aluminum species, while monocyclic products are preferentially formed on the framework Brønsted sites. Similar observations were recently reported for $\alpha$-pinene transformations over dealuminated $\mathrm{Y}$ and mordenite zeolites and unmodified SAPO-5 [19].

Mesoporous silica FSM-16 was used as a catalyst for $\alpha$-pinene isomerization [22]. Selectivity to camphene and limonene was around $40 \%$. Different pretreatment procedure (i.e. calcinations temperature) influenced only activity but not selectivity, similar to results reported for natural zeolite-clinoptilolite [13]. Although selectivity to monocyclic products was also associated with acid sites, application of H-ZSM5, which is known as a strong acid catalyst, did not improve neither activity nor selectivity to limonene, moreover formation of $\alpha$-fenchene (e.g. bicyclic product) was extremely high (with selectivity 19-24\%) [22].

It is fair to state that although the acid catalyzed isomerization of $\alpha$-pinene attracted considerable attention, $\alpha$-pinene isomerization is less studied over ion-exchanged zeolites. Stefanis et al. [23] studied the reactions of $\alpha$-pinene, 


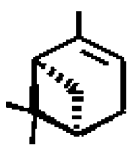

I

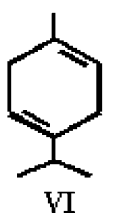

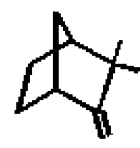

I

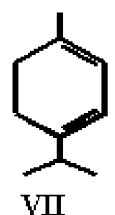

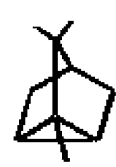

III

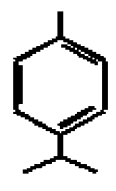

VIII
TV

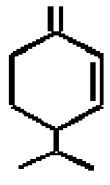

LX

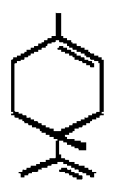

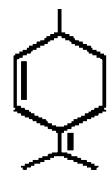

$\mathrm{V}$

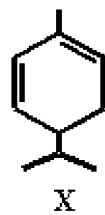

Fig. 1. I: $\alpha$-pinene, II: camphene, III: tricyclene, IV: limonene, V: terpinolene, VI: $\gamma$-terpinene, VII: $\alpha$-terpinene, VIII: $p$-cymene, IX: $\beta$-phellanderene, X: $\alpha$-phellanderene.

limonene and $\alpha$-terpinene in $\mathrm{NH}_{4}{ }^{+}$-ZSM5 $\left(\mathrm{SiO}_{2} / \mathrm{Al}_{2} \mathrm{O}_{3}\right.$ $=35$ and 235), $\mathrm{K}^{+}$-FAZA and $\mathrm{Ca}^{2+}$-FAZA, as well as over USY and BP-alumina pillared clays. FAZA is an ironalumina pillared beidellite-montmorillonite and $\mathrm{K}^{+}$-FAZA and $\mathrm{Ca}^{+}$-FAZA were obtained via cation exchange from acetate solutions. The total conversions for the terpenes followed the order: $\alpha$-pinene $>$ limonene $>\alpha$-terpinene. FAZA displayed high total conversion (86\%) only towards $\alpha$-pinene, while USY (catalyst with strongest acidic properties) was also active in limonene transformations. Nature of exchanged ion had an influence on activity, thus when $\mathrm{K}^{+}$-FAZA showed high activity in $\alpha$-pinene isomerization, $\mathrm{Ca}^{2+}$-FAZA displayed much lower activity even for the more reactive $\alpha$-pinene, which was attributed to pore-blocking effects of $\mathrm{Ca}^{2+}$. USY was selective towards monocyclic products in $\alpha$-pinene isomerization comparing to other materials, although camphene still was the major product.

Our research group previously reported isomerization of $\alpha$-pinene over clinoptilolite [12-16,24]. The objective of the present work is to study the effects of cations $\left(\mathrm{NH}_{4}{ }^{+}\right.$, $\mathrm{Ba}^{2+}$ and $\left.\mathrm{Pb}^{2+}\right)$ in exchanged natural zeolite tuffs rich in clinoptilolite on catalytic properties in the isomerization of $\alpha$-pinene.

As known well, in the ammonium-exchanged zeolites, in general, $\mathrm{Na}^{+}$ions (in zeolite) are replaced with the $\mathrm{NH}_{4}$ ions (in solution). Ion-exchange reaction is carried out as

$$
\begin{aligned}
& \mathrm{NH}_{4}{ }^{+} \text {(solution) }+\mathrm{Na}^{+} \text {(in zeolite) } \\
& \left.\quad \Leftrightarrow \mathrm{NH}_{4}{ }^{+} \text {(in zeolite }\right)+\mathrm{Na}^{+}(\text {solution })
\end{aligned}
$$

When the ammonium-exchanged zeolite was heated at $400{ }^{\circ} \mathrm{C}, \mathrm{H}$-form of zeolite (rich in Brønsted acidities) is obtained, as follows:

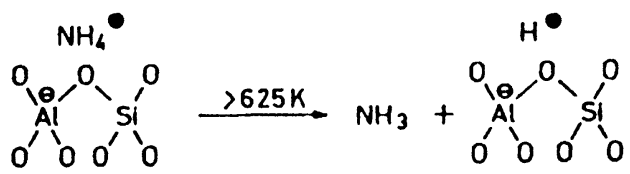

On the other hand, in the ion exchange with ions $\mathrm{Ba}^{2+}$ and $\mathrm{Pb}^{2+}$, Brønsted acid cites are formed by the dissociation of water molecules [25].

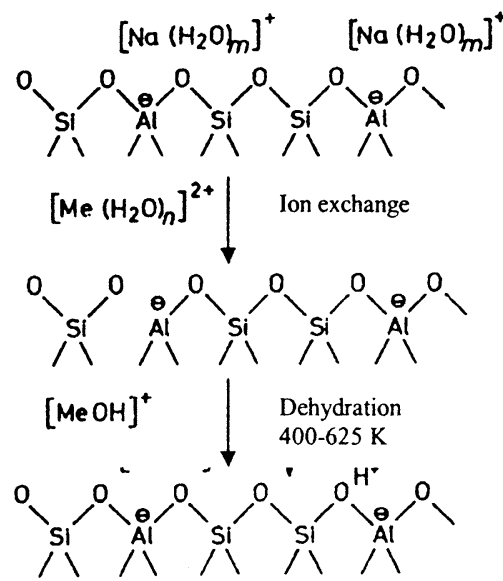

Dissociation equilibrium is

$\mathrm{Me}\left(\mathrm{H}_{2} \mathrm{O}\right)_{\text {zeolite }}^{n+} \Leftrightarrow \mathrm{MeOH}_{\text {zeolite }}^{(n-1)+}+\mathrm{H}_{\text {zeolite }}^{+}$

The selectivity of clinoptilolite for metal ions has been studied extensively. Complete exchange of $\mathrm{Pb}^{2+}$ in the ammonium form and less exchange $\mathrm{Pb}^{2+}$ in the sodium form was observed. The general selectivity series [26] have been suggested as follows:

$$
\begin{aligned}
\mathrm{Cs} & >\mathrm{Rb}>\mathrm{K}>\mathrm{NH}_{4}>\mathrm{Pb}>\mathrm{Ag}>\mathrm{Ba}>\mathrm{Na}>\mathrm{Sr}>\mathrm{Ca} \\
& >\mathrm{Li}>\mathrm{Cd}>\mathrm{Cu}>\mathrm{Zn}
\end{aligned}
$$

\section{Experimental}

\subsection{Catalyst preparation}

Zeolite tuffs rich in clinoptilolite were obtained from Bigadic (Balikesir, Turkey). Prior to ion exchange they were diminished into a grain size of approximately $0.5 \mathrm{~mm}$. Samples were washed twice with distilled water to remove impurities and then suspended in water at room temperature under continuous stirring for $2 \mathrm{~h}$. After filtration samples were dried at $160^{\circ} \mathrm{C}$ for $24 \mathrm{~h}$ in vacuum.

Five grams of zeolite samples pretreated as discussed above were suspended at $25^{\circ} \mathrm{C}$ for $24 \mathrm{~h}$ in $100 \mathrm{ml}$ of an aqueous solution of $\mathrm{NH}_{4} \mathrm{Cl}$ at different concentrations ranged from 0.25 to $6 \mathrm{M}$. Analogously $2 \mathrm{~g}$ of zeolite samples were put in contact with $50 \mathrm{ml}$ of $\mathrm{BaCl}_{2}$ in different concentration $(0.1,0.5$ and $1 \mathrm{M})$ at $25^{\circ} \mathrm{C}$ for 7 days. After filtration, the samples were washed with distilled water until $\mathrm{Cl}^{-}$free conditions and calcined at $400{ }^{\circ} \mathrm{C}$ for $4 \mathrm{~h}\left(\mathrm{NH}_{4}{ }^{+}\right)$or dried in vacuum at $160^{\circ} \mathrm{C}$ for $24 \mathrm{~h}\left(\mathrm{Ba}^{2+}\right)$.

$\mathrm{Pb}$-rich zeolite was obtained via cation exchange from 0.1 or $0.5 \mathrm{M}$ nitrate solutions. One gram of $\mathrm{NH}_{4}$ zeolite prepared with 0.5 or $1.5 \mathrm{M} \mathrm{NH}_{4} \mathrm{Cl}$ solution was then contacted with $20 \mathrm{ml}$ of 0.1 or $0.5 \mathrm{M} \mathrm{Pb}\left(\mathrm{NO}_{3}\right)_{2}$ solution at $25^{\circ} \mathrm{C}$ for $24 \mathrm{~h}$. 
Additionally different amounts of $\mathrm{PbO}(1,5$ and $10 \%$ in weight) or $\mathrm{BaO}(1.3,3.3$ and $10 \%$ in weight in the mixture) were mechanically mixed with a natural zeolite in a glass reactor until homogeneity of the mixture was achieved. To this end the mixture prepared was stirred vigorously, the speed of the stirrer was kept constant, but the direction of angular velocity was changed periodically to prevent the mixture to be heaped at the surface of the reactor.

\subsection{Reaction studies}

Prepared catalysts were tested in the isomerization reaction of $\alpha$-pinene. Reaction was carried out at atmospheric pressure under nitrogen flow in a glass reactor with a reflux condenser, an efficient stirrer and a temperature controller (Fig. 2). One gram of catalyst and $50 \mathrm{ml}$ of wood turpentine (Ortas, Edremit, Turkey) containing 85 wt. $\% \alpha$-pinene were charged in the reactor. Adding the catalyst, the reaction was started and all experiments were carried out under isothermal $\left(155^{\circ} \mathrm{C}\right)$ conditions. Samples of the reaction mixture were taken during the course of the reaction and analyzed by flame ionization detector (FID) gas chromatography (Hewlett-Packard 5980/2 with $25 \mathrm{~m}$ and $0.32 \mathrm{~mm}$ i.d. HP-FFAP capillary column) connected to a mass spectrometer with electron energy $70 \mathrm{eV}$ and mass rate $35-425 \mathrm{~m} / \mathrm{z}$. Temperature programming (increase at a rate of $2{ }^{\circ} \mathrm{C} / \mathrm{min}$ from 60 to $130^{\circ} \mathrm{C}$ and onwards at a rate $3{ }^{\circ} \mathrm{C} / \mathrm{min}$ until $215^{\circ} \mathrm{C}$ ) was applied for separation at $1 \mathrm{ml} / \mathrm{min} \mathrm{N}_{2}$ flow. A kinetic run took $3 \mathrm{~h}$.

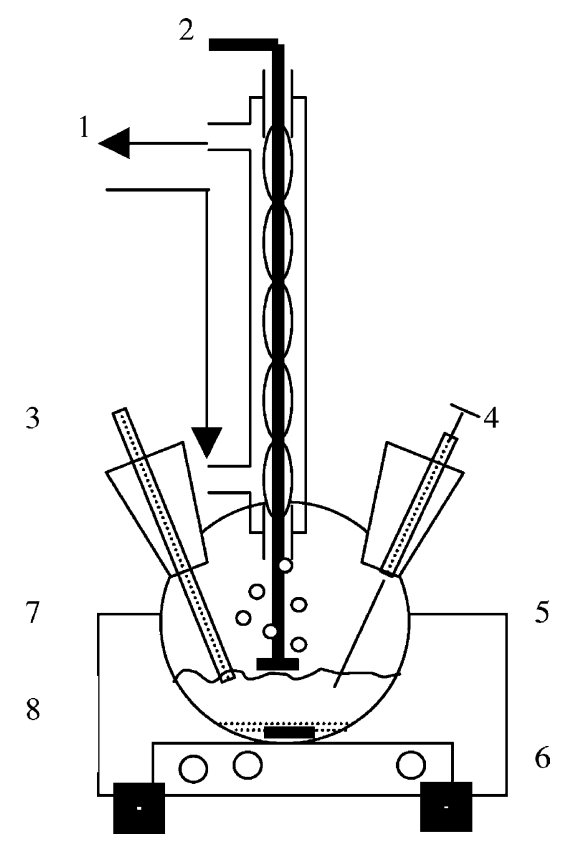

Fig. 2. The schematic diagram of the experimental system-1: inert gas transfer line; 2: condenser; 3: thermometer; 4: sampling syringe; 5: heater; 6: control panel; 7: three-neck flask; 8: reaction mixture (turpentine, catalyst) and magnetic bar.

\subsection{Catalyst characterization}

Surface areas and pore volumes were obtained from the nitrogen adsorption isotherms measured at $77 \mathrm{~K}$ in a static volumetric apparatus (Coulter Omnisorp 100cx) up to $P / P_{0}$ $\sim 0.95$.

The chemical analysis of the natural zeolite was done by atomic absorption except gravimetrically analysis of $\mathrm{SiO}_{2}$ and water. The chemical composition found is $74.86 \% \mathrm{SiO}_{2}$, $0.42 \% \mathrm{FeO}, 0.7 \% \mathrm{MgO}, 0.5 \% \mathrm{Na}_{2} \mathrm{O}, 2.71 \% \mathrm{~K}_{2} \mathrm{O}, 9.04 \%$ $\mathrm{H}_{2} \mathrm{O}, 2.42 \% \mathrm{CaO}, 9.35 \% \mathrm{Al}_{2} \mathrm{O}_{3}$ (by weight). IR spectrum of the zeolite catalysts were recorded on $\mathrm{KBr}$ wafers $(1.2 \mathrm{mg}$ catalyst and $150 \mathrm{mg} \mathrm{KBr}$ ) with a Shimadzu 470 Instrument. IR analysis took place at room temperature and atmospheric pressure.

Hammett indicators were used for the measurement of acid strength of some catalyst samples. The acid strength was expressed by the Hammett acidity function $H_{0}$. Lower values of $H_{0}$ correspond to greater acid strength of the solid.

Pyridine adsorption was carried out to identify the acid centers of the catalysts. For these purpose, pyridine was adsorbed on dried samples for 1 day prior to measurements. After that, excess amount of pyridine was vaporized in vacuum for $48 \mathrm{~h}$ at $50^{\circ} \mathrm{C}$. Wafers were prepared by using $\mathrm{KBr}$ pressed disk technique ( $8 \mathrm{mg}$ catalyst/100 $\mathrm{mg} \mathrm{KBr}$ ).

$\mathrm{X}$-ray diffraction studies were carried out for some catalyst samples on a Jeol JSDX 100S4 diractometer using $\mathrm{Cu} \mathrm{K} \alpha$ radiation with a Ni filter. The differential scanning calorimeter (DSC) was used in thermal analysis of some catalyst samples. Before DSC studies, the samples were kept in atmosphere of saturated $\mathrm{NH}_{4} \mathrm{Cl}$ solution at $25^{\circ} \mathrm{C}$ for $20 \mathrm{~h}$. The DSC analysis of samples, in equilibrium with $75 \%$ relative humidity atmosphere at $25^{\circ} \mathrm{C}$, were made by heating them $5{ }^{\circ} \mathrm{C} / \mathrm{min}$ rate from 25 to $400^{\circ} \mathrm{C}$ using Setaram DSC 92 under nitrogen flow rate of $75 \mathrm{~cm}^{3} / \mathrm{min}$. The mass loss in samples were determined by weighing them before and immediately after heating.

\section{Results}

\subsection{Reaction studies}

The typical kinetic curves are presented in Fig. 3. The main reaction products in accordance to the previous studies were camphene and limonene while tricyclene, fenchene, terpinolene, $p$-cymene, or $\alpha$ - and $\gamma$-terpinene were also formed.

Kinetic studies over a clinoptilolite catalyst [13,24] showed that when $\alpha$-pinene is consumed, camphene slowly undergoes isomerization into tricyclene, finally achieving equilibrium concentration. Also, at high conversions, limonene isomerizes into secondary products. Selectivity was found to be virtually independent of pressure and temperature [24] and calcinations temperature [13], although the reaction rate depended on these parameters. Calcination 


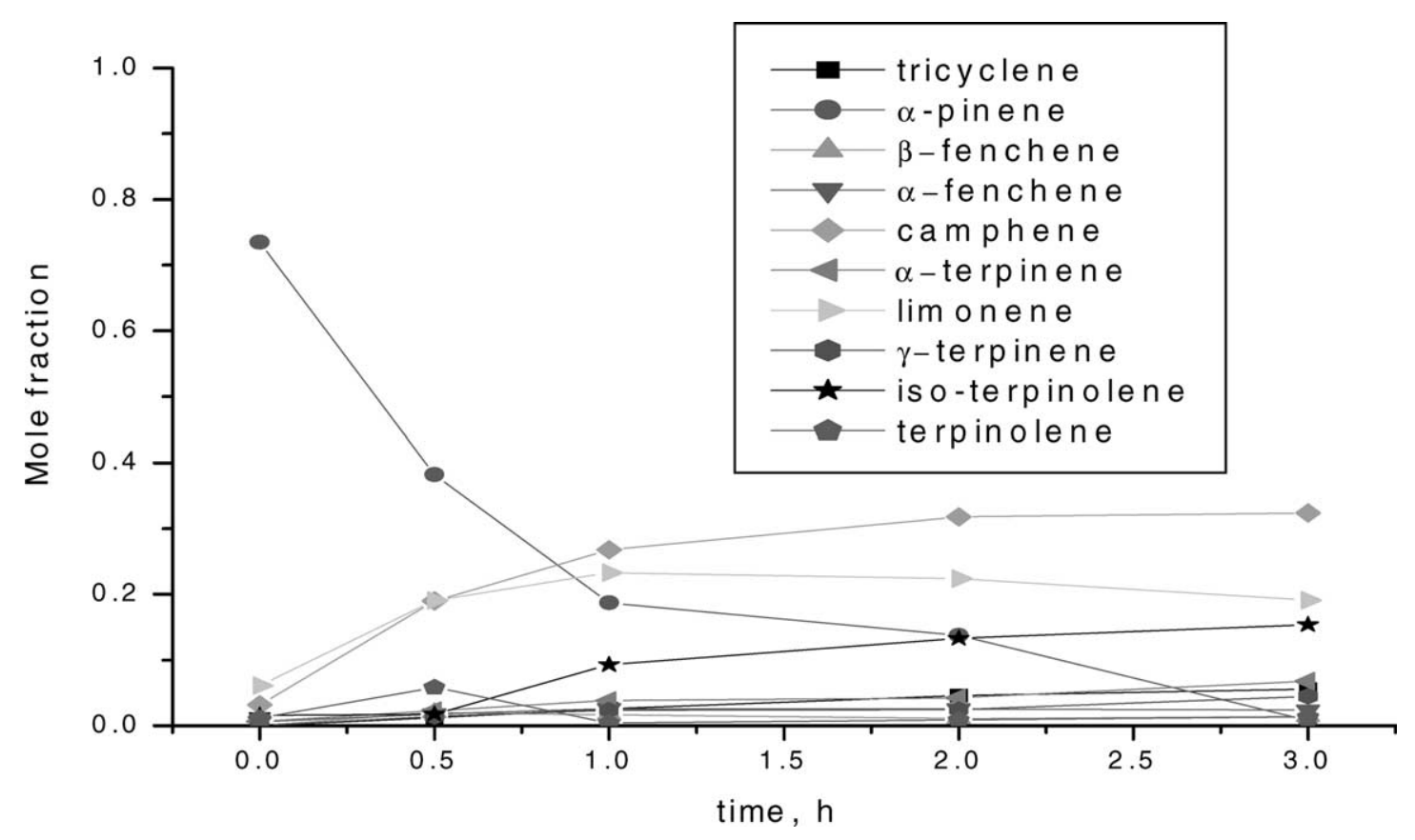

Fig. 3. Isomerization of $\alpha$-pinene over unmodified zeolite at $155^{\circ} \mathrm{C}$.

procedure led to a loss of some acid sites, therefore decreasing the turnover number, but not altering the reaction mechanism.

The key intermediate in $\alpha$-pinene isomerization is the pinylcarbonium ion [24], which is versibly from $\alpha$-pinene and is the precursor for all of the reaction products, which are produced in turn in consequent steps. Mono- and tricyclic terpenes are formed from this ion in parallel irreversible steps. Thus, the routes leading to camphene and tricyclene on one side, and limonene and its secondary products on the other side, are not interconnected. This part of the reaction network can be depicted very crudely as follows:

$$
\begin{aligned}
& \text { camphene } \leftrightarrow \text { trciyclene } \\
& \alpha \text {-pinene } \rightarrow \text { pinylcarbonium ion }
\end{aligned}
$$

$$
\text { limonene } \rightarrow \text { secondary products }
$$

More detailed network is presented in Fig. 4. Initial reaction rate and selectivity values at the beginning of experiments when secondary reactions can be neglected (duration $0.5 \mathrm{~h}$ ) are presented for studied catalysts in Table 1 .

Selectivity to camphene and limonene were determined in the following ways:

selectivity to any product

$$
=S_{\mathrm{C}}\left(S_{\mathrm{L}}\right)=\frac{\text { moles of product } \mathrm{C} \text { or } \mathrm{L} \text { formed }}{\text { moles of converted of } \alpha \text {-pinene }} \times 100
$$

It can be stated as a trend that activity of catalysts as well as total conversion of $\alpha$-pinene increases with increasing concentration of $\mathrm{NH}_{4}{ }^{+}$solution (entries 6 and 7) and complete conversion of $\alpha$-pinene after $3 \mathrm{~h}$ is obtained over the catalysts prepared by ion exchange with $\mathrm{NH}_{4}{ }^{+}>4 \mathrm{M}$. $\mathrm{Pb}$-rich zeolites obtained via cation exchange from entries 8-11 (in Table 1) also displayed high reaction rate, while mixing of $\mathrm{PbO}$ with a natural zeolite mechanically (entries 12-14 in Table 1) caused a substantial decrease in catalytic activity. Ba-rich zeolites, which were prepared with ion exchange, had higher activities compared to the parent zeolite. Interesting to note that mechanic mixing with $\mathrm{BaO}$ did not cause a decrease in catalytic activity.

Camphene and tricyclene were the main bi- and tricyclic products in $\alpha$-pinene isomerization. In only few cases initial selectivity to camphene differed from the final one, however, selectivity to bi- and tricyclic products was almost independent of conversion on all studied catalysts irrespectively of the type of zeolite. Fig. 5 presents the concentrations of camphene and tricyclene as a function of $\alpha$-pinene conversion for all studied catalysts.

Similar dependencies were already reported in the literature $[13,22]$. At the same time selectivity to monocyclic product was very much dependent on conversion due to secondary reactions of limonene.

Selectivity to limonene was seen to be dependent on $\alpha$-pinene conversion (Figs. 6-8). Catalysts prepared by ion exchange with $\mathrm{NH}_{4}{ }^{+}$displayed lower selectivity to limonene at the same conversion due to higher rates of secondary reactions. Mechanical mixing with $\mathrm{PbO}$ did not influence selectivity (curve 14, Fig. 7). Ba-rich zeolites possessed high selectivity towards limonene up to high conversions of 


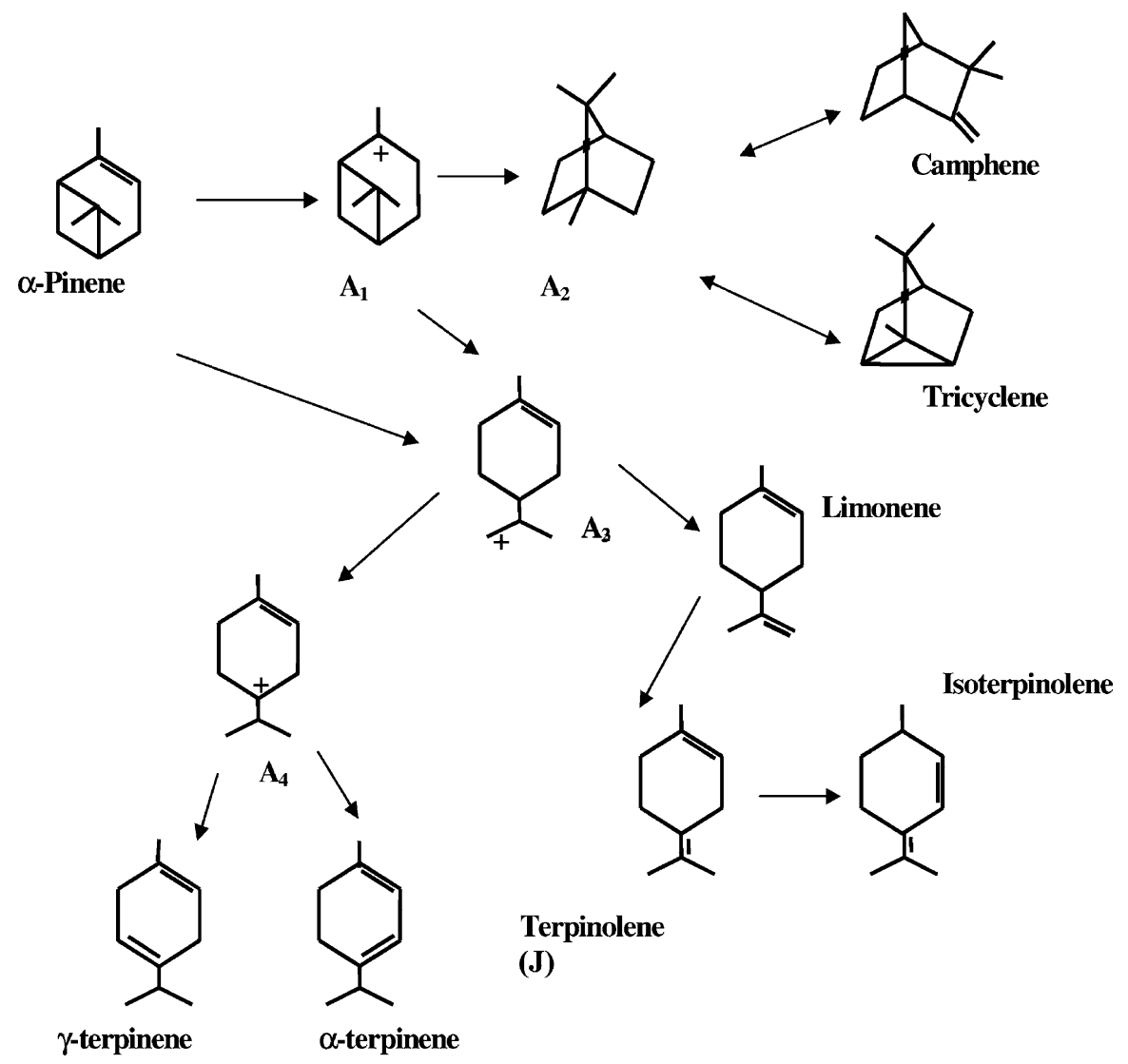

Fig. 4. Reaction network.

Table 1

Conversions and selectivity calculated for different pretreated zeolite catalysts $\alpha$-pinene isomerization

\begin{tabular}{|c|c|c|c|c|c|c|c|}
\hline Entry number & Catalyst & $r^{i}(\mathrm{~mol} / \mathrm{gh})$ & $S_{\mathrm{C}}^{i}$ & $S_{\mathrm{L}}^{i}$ & $X_{\text {pinene }}^{*}$ & $S_{\mathrm{C}}^{*}$ & $S_{\mathrm{L}}^{*}$ \\
\hline 1 & Natural zeolite (Zeo.) & 0.27 & 42.5 & 30 & 98.9 & 40.2 & 17.9 \\
\hline 2 & Zeo.- $\left(0.25 \mathrm{M} \mathrm{NH}_{4}^{+}\right)$ & 0.25 & 40.6 & 29.4 & 91.9 & 40.6 & 21.5 \\
\hline 3 & Zeo.- $\left(0.5 \mathrm{M} \mathrm{NH}_{4}^{+}\right)$ & 0.41 & 37.4 & 25 & 98.5 & 35.9 & 8.7 \\
\hline 4 & Zeo.- $\left(1 \mathrm{M} \mathrm{NH}_{4}^{+}\right)$ & 0.37 & 42.5 & 25 & 98.8 & 38.2 & 11.8 \\
\hline 5 & Zeo.- $\left(2 \mathrm{M} \mathrm{NH}_{4}^{+}\right)$ & 0.30 & 38.3 & 27.3 & 99.1 & 35.9 & 9.2 \\
\hline 6 & Zeo.- $\left(4 \mathrm{M} \mathrm{NH}_{4}^{+}\right)$ & 0.54 & 38 & 13 & 100 & 38.4 & $\mathrm{NC}$ \\
\hline 7 & Zeo.- $\left(6 \mathrm{M} \mathrm{NH}_{4}{ }^{+}\right.$ & 0.55 & 39.6 & 14.6 & 100 & 38.7 & NC \\
\hline 8 & Zeo.- $\left(0.5 \mathrm{M} \mathrm{NH}_{4}{ }^{+} / 0.1 \mathrm{M} \mathrm{Pb}^{2+}\right)$ & 0.59 & 33.4 & 6.1 & 100 & 33.3 & $\mathrm{NC}$ \\
\hline 9 & Zeo.- $\left(1.5 \mathrm{M} \mathrm{NH}_{4}^{+} / 0.1 \mathrm{M} \mathrm{Pb}^{2+}\right)$ & 0.46 & 41.9 & 16.6 & 99.3 & 37.3 & $\mathrm{NC}$ \\
\hline 10 & Zeo. $-\left(0.5 \mathrm{M} \mathrm{NH}_{4}+/ 0.5 \mathrm{M} \mathrm{Pb}^{2+}\right)$ & 0.56 & 37.3 & 16.6 & 91.6 & 41.8 & 25.4 \\
\hline 11 & Zeo.- $\left(1.5 \mathrm{M} \mathrm{NH}_{4}{ }^{+} / 0.5 \mathrm{M} \mathrm{Pb}^{2+}\right)$ & 0.49 & 39.9 & 10.3 & 99.4 & 31.1 & $\mathrm{NC}$ \\
\hline 12 & Zeo.-(PbO 1 wt. $\%)$ & 0.047 & 49.8 & 31 & 50.9 & 49.97 & 30.9 \\
\hline 13 & Zeo.-(PbO 5 wt. $\%)$ & 0.068 & 43.2 & 28.8 & 67.7 & 41.4 & 28.8 \\
\hline 14 & Zeo.-(PbO 10 wt.\%) & 0.055 & 43.3 & 27.2 & 54.1 & 43.4 & 27.2 \\
\hline 15 & Zeo.- $\left(0.1 \mathrm{M} \mathrm{Ba}^{2+}\right)$ & 0.53 & 39.3 & 26.2 & 100 & 34.4 & 2.6 \\
\hline 16 & Zeo.- $\left(0.5 \mathrm{M} \mathrm{Ba}^{2+}\right)$ & 0.48 & 39.2 & 30 & 99.3 & 35.2 & $\mathrm{NC}$ \\
\hline 17 & Zeo.- $\left(1 \mathrm{M} \mathrm{Ba}^{2+}\right)$ & 0.43 & 38.3 & 31.2 & 100 & 34.4 & 2.6 \\
\hline 18 & Zeo.-(BaO 1.33 wt.\%) & 0.32 & 41.3 & 40.2 & 100 & 40.0 & 27.3 \\
\hline 19 & Zeo.-(BaO 3.3 wt.\%) & 0.57 & 38.2 & 30.6 & 100 & 34.2 & 5.7 \\
\hline 20 & Zeo.-(BaO 10 wt.\%) & 0.33 & 44.2 & 40 & 100 & 39.5 & 21.2 \\
\hline
\end{tabular}

$S_{\mathrm{C}}^{*}$ and $S_{\mathrm{L}}^{*}$ : selectivity towards camphene and limonene, $X_{\text {pinene }}^{*}:$ pinene mole fraction, $i$ : initial (corresponds to $0.5 \mathrm{~h}$ reaction time), $*:$ final $(3 \mathrm{~h}$ reaction time). 


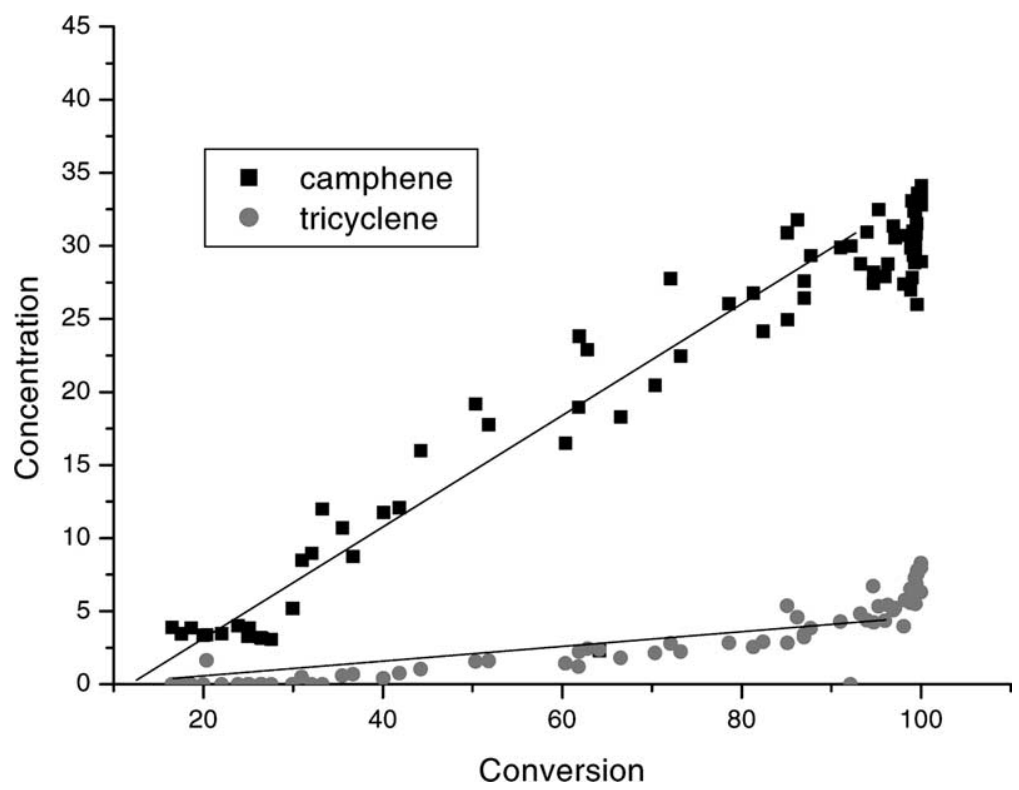

Fig. 5. Concentration of tricyclic products as a function of $\alpha$-pinene conversion for all studied catalysts.

$\alpha$-pinene with the highest value (ca. 30\%) obtained for mechanically mixed catalysts.

Monocyclic terpenes, where the cycles contain six carbon atoms: limonene, terpinolene, $\alpha$ - and $\gamma$-terpinenes are formed from pinylcarbonium ion. The latter captures electron pair, which constitute the bond between $\mathrm{C}_{5}$ and $\mathrm{C}_{7}$ atoms and forms a double bond between $\mathrm{C}_{4}$ and $\mathrm{C}_{5}$ atoms. $\mathrm{H}^{+}$escapes this terpenylcarbonium ion leading to limonene. There is a possibility of a charge transfer within terpenylcarbonium ion from $\mathrm{C}_{7}$ to $\mathrm{C}_{1}$ atom, which (after proton subtraction) gives $\gamma$ - and $\alpha$-terpinenes. Double bond migration in limonene results subsequently in terpinolene and isoterpinolene formation.

A sharp decrease in limonene concentration in the reaction mixture was obtained with increasing concentration of $\mathrm{NH}_{4}{ }^{+}$-exchange solution (Fig. 9a), which means that secondary reactions proceed faster comparing to the untreated original zeolite. However, as concentration of $\mathrm{Ba}^{2+}$-exchange solution increases, a slight increase in limonene concentration is observed. It is just the opposite what is observed with $\mathrm{NH}_{4}{ }^{+}$-exchanged zeolites. This increase in limonene concentration is likely to be due to

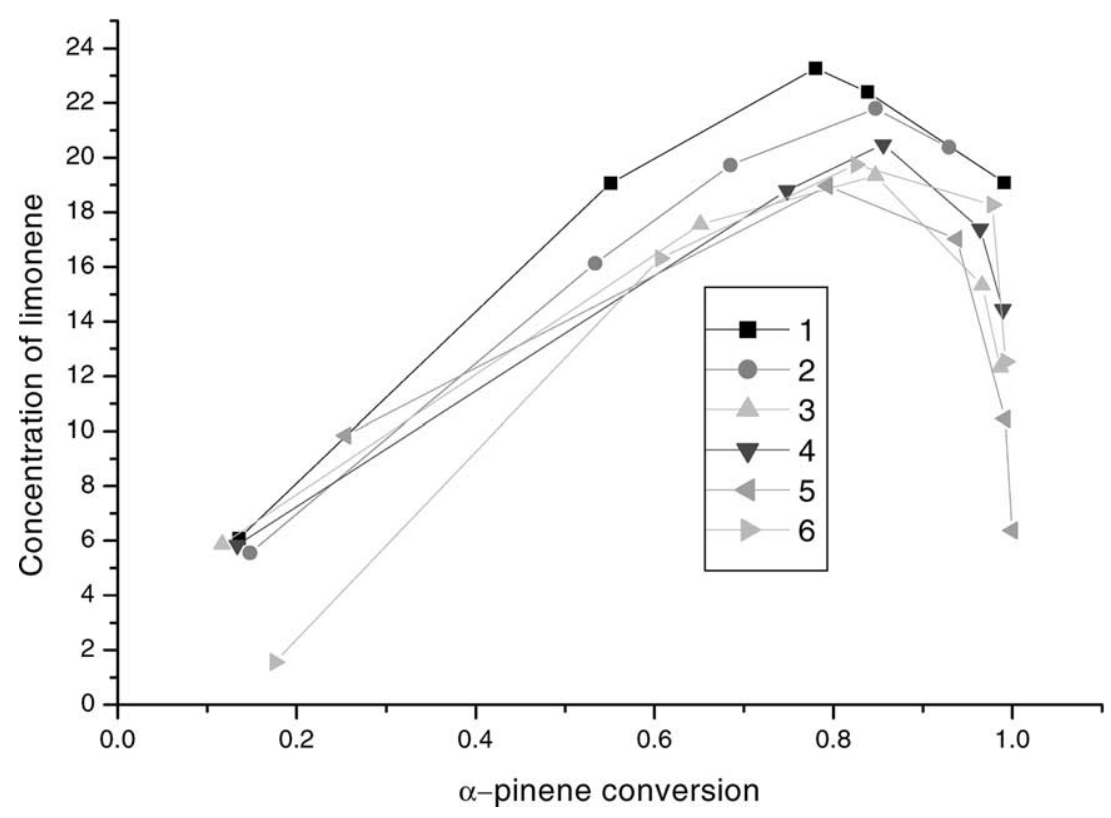

Fig. 6. Limonene mole fraction as a function of $\alpha$-pinene conversion. Legend number corresponds the entry number in Table 1. 


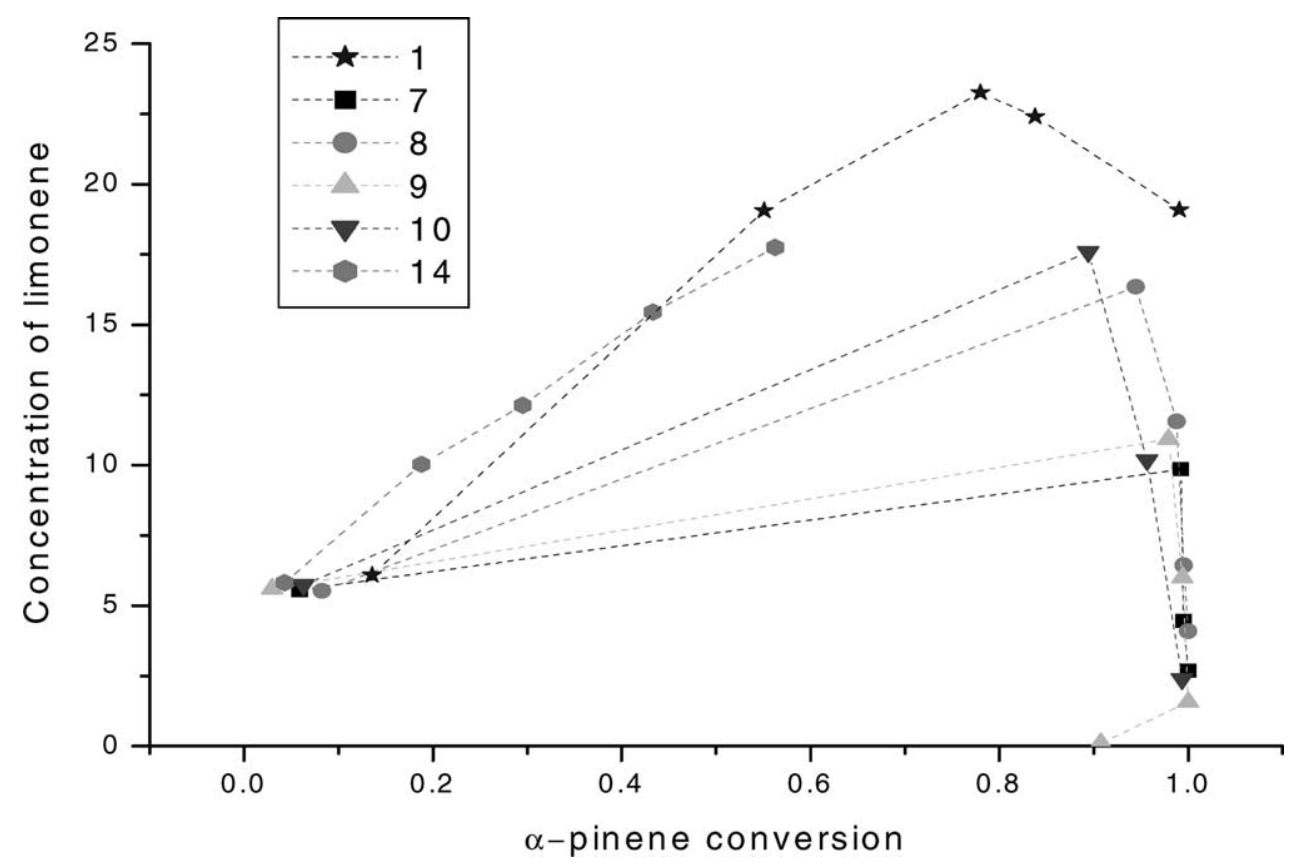

Fig. 7. Limonene mole fraction as a function of $\alpha$-pinene conversion. Legend number corresponds the entry number in Table 1.

the increase of Brønsted acidity of zeolite (Fig. 9b) with increasing concentration of $\mathrm{Ba}^{2+}$-solution.

\subsection{Kinetic studies}

Many authors usually report the isomerization products as total sum of mono- and tricyclic products and detailed kinetic studies are rather sparse in $\alpha$-pinene isomerization. This reaction was reported to be of zero order by Rudakov et al. [27]. First-order dependence of $\alpha$-pinene consumption was reported [24], activation energy was determined to be $80.9 \mathrm{~kJ} /$ mole. Elementary step mechanism was advanced $[13,14]$ and selectivity was modeled on the basis of it. In the present study, we investigated only $\alpha$-pinene consumption kinetics over zeolites exchanged with $\mathrm{NH}_{4}{ }^{+}$.

Vigorous stirring helps to eliminate the external diffusion resistance between the bulk liquid and the catalyst surface. The turbulence created by nitrogen stream around the

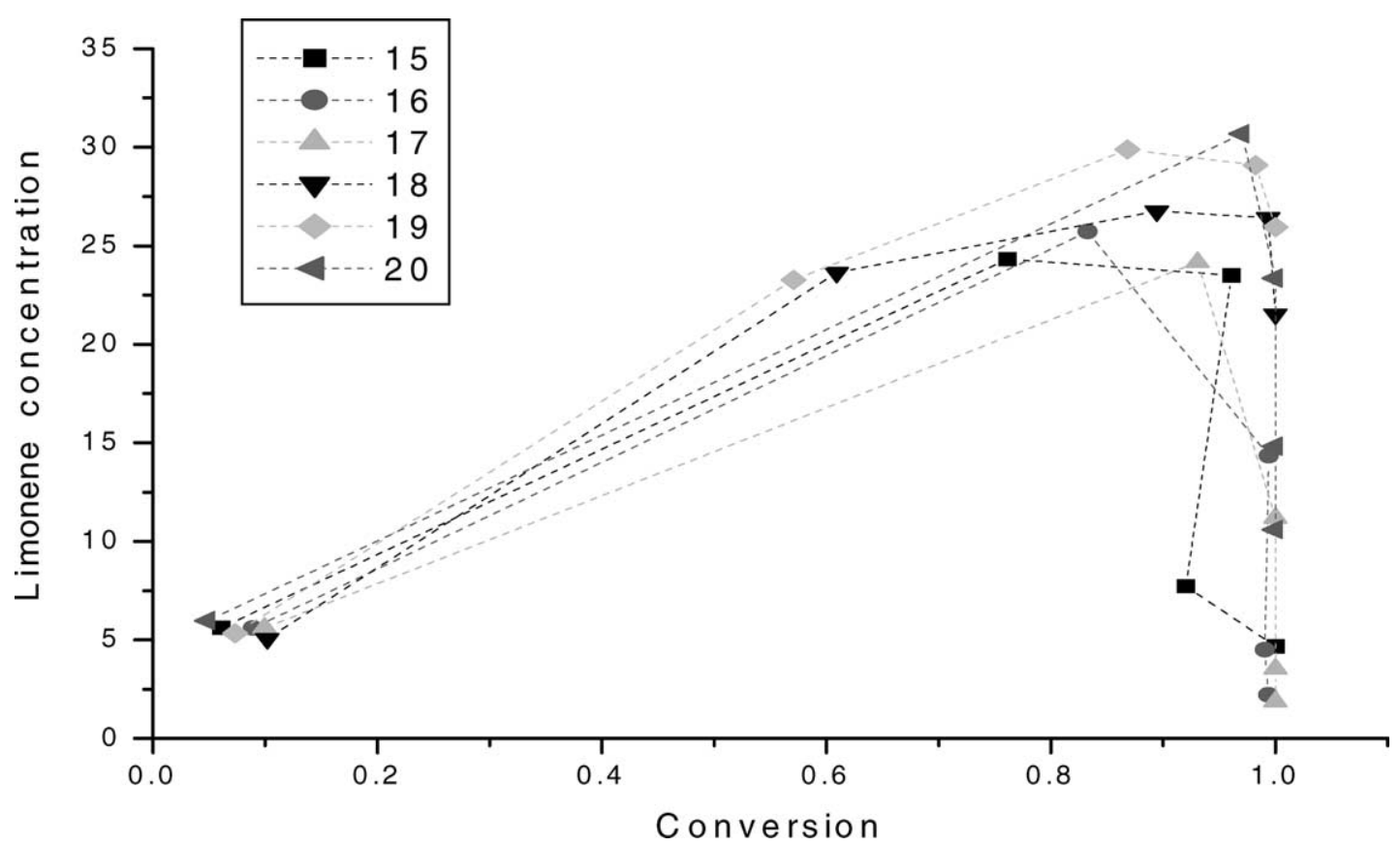

Fig. 8. Limonene mole fraction as a function of $\alpha$-pinene conversion. Legend number corresponds the entry number in Table 1. 

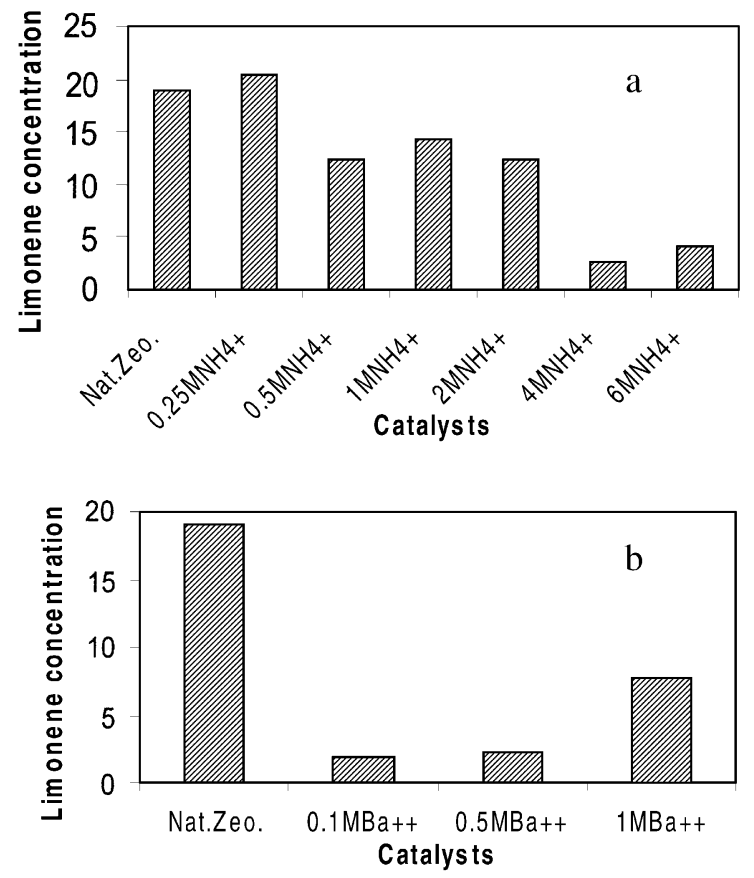

Fig. 9. Limonene concentration at the end of run (3h) for $\mathrm{NH}_{4}{ }^{+}$(a) and for $\mathrm{Ba}^{2+}$-exchanged catalysts (b).

catalyst particles also helps to eliminate the external diffusion resistance. Due to the small size of catalyst particles, internal diffusion resistance is also negligible, The value of the Thiele modulus was calculated for a first-order consumption kinetics of $\alpha$-pinene and was found to be 0.1 , indicating that effectiveness factor was equal to 1 . The following rate equations were tested for kinetic analysis:

$\frac{\mathrm{d} C}{\mathrm{~d} t}=k C$ for $n=1$

$\frac{C_{\mathrm{A}}^{1-n}-C_{\mathrm{A} 0}^{1-n}}{n-1}=k t$ for $n \neq 1$

Eq. (4) was tested for $n=1.5,0$ and 0.5. A first-order dependency on $\alpha$-pinene consumption was observed on the
$\mathrm{NH}_{4}{ }^{+}$-exchanged zeolite catalysts (Fig. 10). Reaction rate constant was found to be equal to $1.30 \mathrm{~h}^{-1}$ with a correlation coefficient of $R^{2}=0.86$ for all the $\mathrm{NH}_{4}{ }^{+}$concentrations used in ion exchange. Regression coefficient was much greater than 0.90 for a catalyst sample prepared at any individual $\mathrm{NH}_{4}{ }^{+}$concentration.

\subsection{IR, $N_{2}$ adsorption DSC, XRD and acidity studies}

The IR spectrum for the H-rich zeolites are given in Fig. 11. It can be seen from the figure that ammonium deformation band at $1400 \mathrm{~cm}^{-1}$ is still present after thermal treatment at $400^{\circ} \mathrm{C}$ for $4 \mathrm{~h}$. This is an indication that completely H-rich zeolite could not be obtained after this thermal treatment.

Nitrogen adsorption isotherms for original and modified natural zeolites are classified to be type 2 according to Brunauer [28]. The maximum amounts of nitrogen adsorbed on all modified zeolites at maximum relative pressure $P / P_{0}=0.9$ are clearly lower than that on parent zeolite (Fig. 12). Pb-rich zeolite displayed intermediate behavior.

Nitrogen adsorption data were evaluated and mono layer surface area and half width of pores were calculated by using Langmuir and Dubinin-Astakhov (DA) methods [29,30].

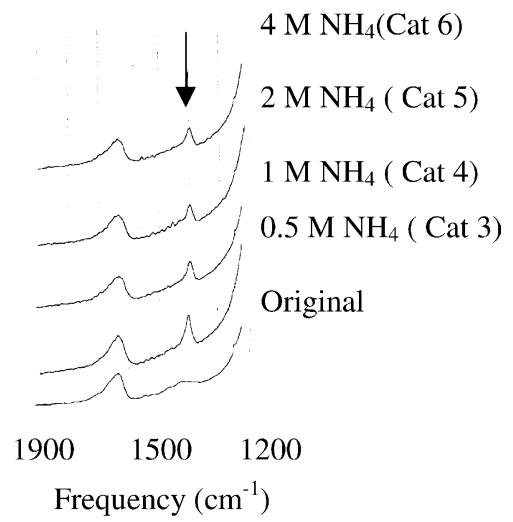

Fig. 11. Infrared spectrum between 1900 and $1200 \mathrm{~cm}^{-1}$ of original and $\mathrm{NH}_{4} \mathrm{Cl}$ treated zeolites (after calcination at $400^{\circ} \mathrm{C}$ for $4 \mathrm{~h}$ ).

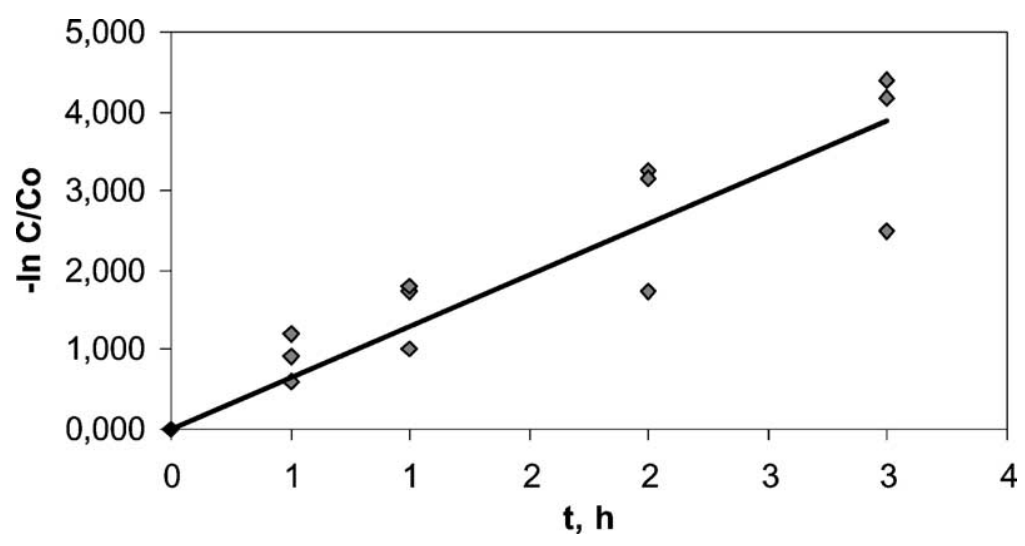

Fig. 10. First-order dependency on $\alpha$-pinene consumption on the $\mathrm{NH}_{4}{ }^{+}$-exchanged zeolite. 


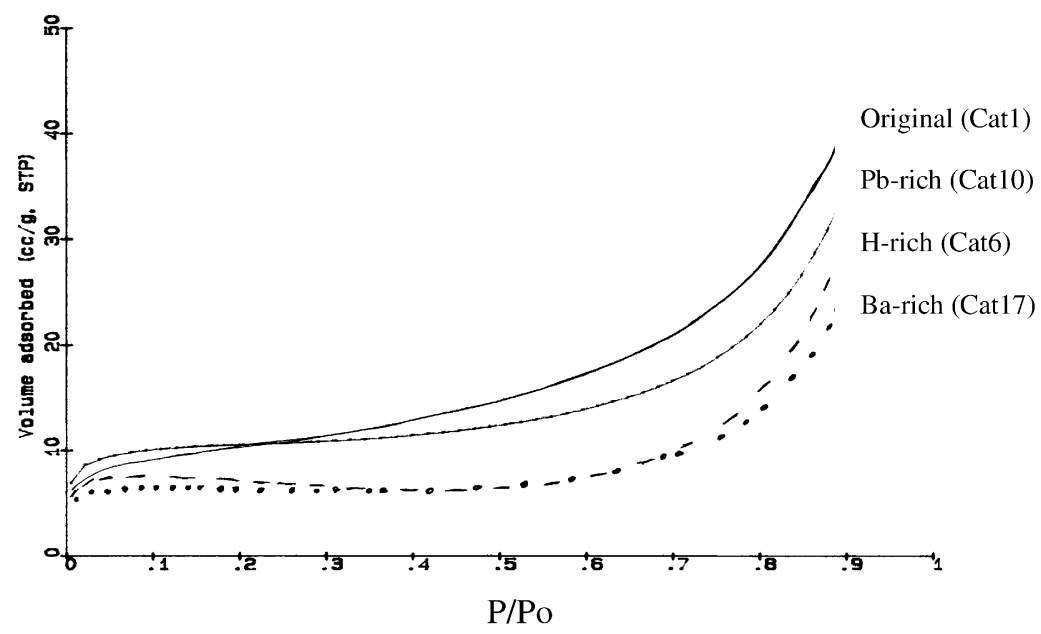

Fig. 12. Nitrogen adsorption isotherms for original and modified natural zeolites.

Fig. 13 shows that Ba-, $\mathrm{H}$ - and $\mathrm{Pb}$-rich zeolites have lower mono layer surface areas and pore size diameters than those of original zeolite before modification.But half width of pore for Ba-rich zeolite could not be calculated by means of DA method. This shows that adsorption on Ba-rich zeolite at low pressure $\left(P / P_{0}<0.1\right)$ is as layer by layer surface coverage rather than as a volume filling of the adsorption space.

Fig. 14 presents dehydration heat amounts of several cation-exchanged zeolites. It shows that cation-rich zeolites have lower dehydration energies than original zeolite. This means that more homogeneous zeolites with wider pores were obtained with cation exchange. As seen from the figure the percentage of moisture loss for original zeolite is lower than those for $\mathrm{Pb}-, \mathrm{H}-, \mathrm{Ba}-$ forms. The moisture loss is related to the heating rate, atmosphere over the sample size of pore, cation-water distance in the pore. Adsorbents with higher pore sizes can desorb water easily. It is expected that H-rich zeolite has higher pore size than original one because of the decationization of the pores of zeolite. However, this could not be observed because completely H-rich zeolite could not be obtained. Lead and barium ions are large diva-

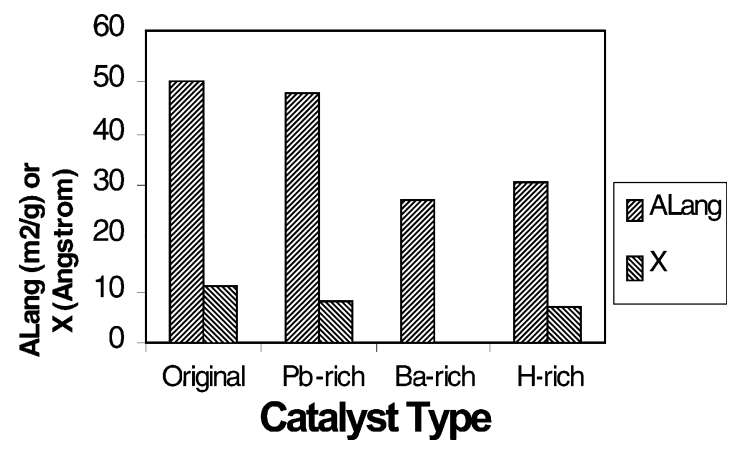

Fig. 13. Effect of cation exchange on nitrogen adsorption properties ALang: Langmuir surface area, X: half width of pores (DubininAstakhov). lent cations (radius: 1.23 and $1.38 \AA$, respectively) and their exchange with cations present $\left(0.95 \AA\right.$ for $\mathrm{Na}^{+}, 0.9 \AA$ for $\mathrm{Ca}^{2+}, 1.33 \AA$ for $\mathrm{K}^{+}, 0.65 \AA$ for $\mathrm{Mg}^{2+}$ ) in zeolite causes the enlargement of the zeolite pores. It follows from this lower moisture loss for original zeolite that the heating up to $400^{\circ} \mathrm{C}$ was not enough to remove "tightly bound water" which is adsorbed in the very small pores [31].

Fig. 15 illustrates the XRD patterns of some ion-exchanged zeolites. No different diffraction peaks were observed if $\mathrm{NH}_{4}{ }^{+}$concentration remained below $1 \mathrm{M}$, but when the $\mathrm{NH}_{4}{ }^{+}$concentration reached $1 \mathrm{M}$, the peaks at about $2 \theta=$ $17.5^{\circ}$ (characteristic for clinoptilolite (C) and Heulandite $(\mathrm{H})$ ) and $2 \theta=13^{\circ}$ (characteristic for $\mathrm{C}$ ) became more appreciable. During the deammoniation, the heating rate, $5^{\circ} \mathrm{C} / \mathrm{min}$, was so slow that any diminution in crystallinity was not expected [26], which was supported by XRD studies. The decrease measured in the surface areas of H-rich (Cat. 6) zeolites depends on the incomplete deammoniation. Zeolite sample exchanged with $\mathrm{Pb}^{2+}$ (Cat. 10) exhibited a sharp destruction at about $2 \theta=10^{\circ}$ (characteristic for $\mathrm{H}$ and $\mathrm{C}$ ). Similar destructions were observed with zeolite sample exchanged with $1 \mathrm{M} \mathrm{BaCl}_{2}$ solution, at about $2 \theta=22.5^{\circ}$ (characteristic for $\mathrm{C}$ and $\mathrm{H}$ ) and $2 \theta=30^{\circ}$ (characteristic for peaks of $\mathrm{H}$ and $\mathrm{C}$ ), respectively. The decrease in the intensity of the corresponding peaks shows that ion exchange with $\mathrm{Pb}^{2+}$ and $\mathrm{Ba}^{2+}$ causes crystallinity diminution resulting in the decrease of surface area. These XRD reflections are supported by the nitrogen adsorption data given in Figs. 12 and 13.

The acid strength of ion-exchanged zeolites was found to be between $H_{0}=6.8$ and $H_{0}=-0.29$. Infrared spectroscopic studies of ammonia and pyridine adsorbed on solid surfaces make it possible to distinguish between Brønsted and Lewis acids and to assess their amounts independently. In this study, pyridine was used as proton acceptor. The spectrum of pyridine coordinatively bounded to the surface (Lewis acidity) is very different from that of the pyridinium 


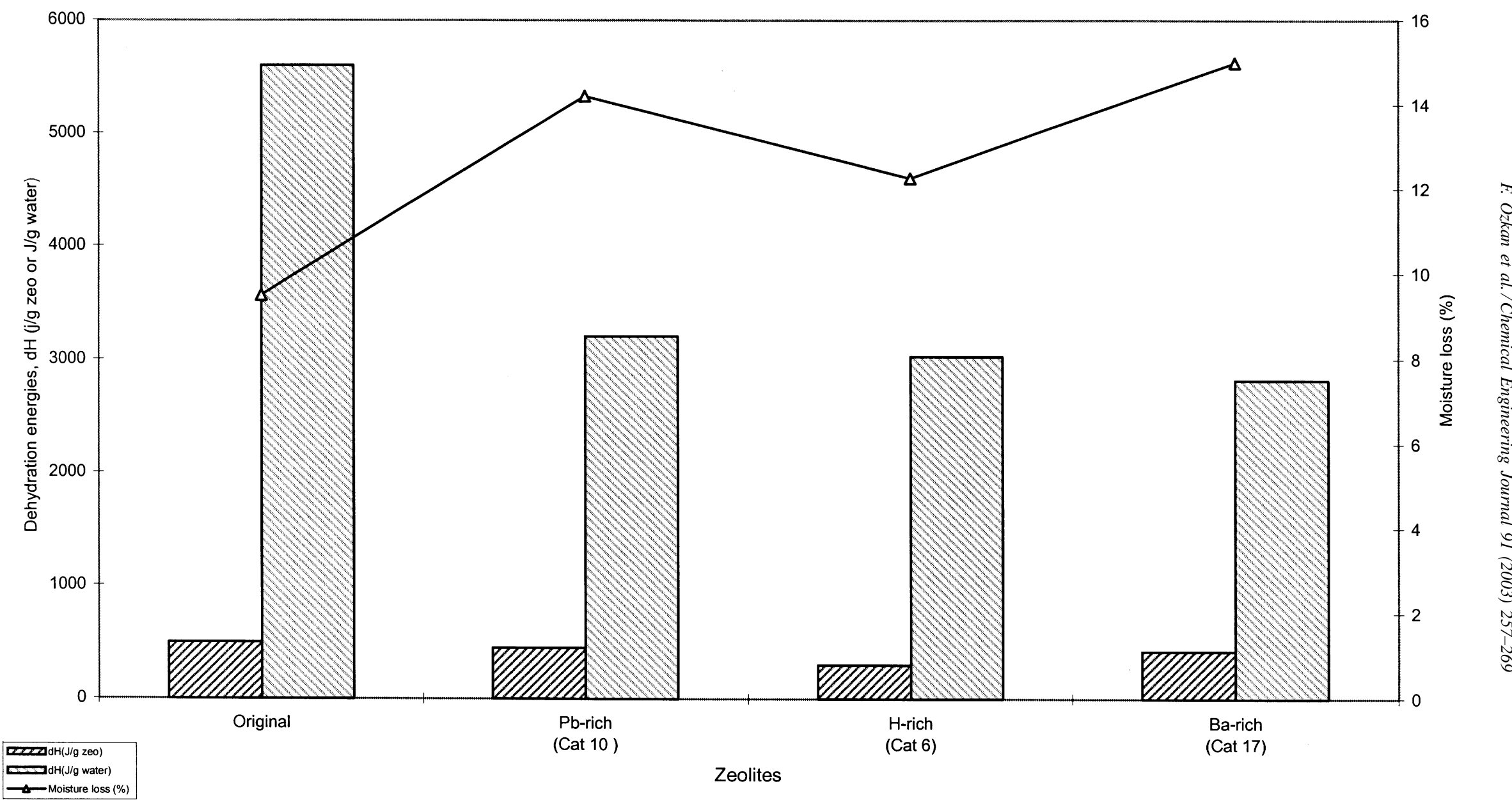

Fig. 14. Dehydration properties of original and cation-exchanged zeolites. 


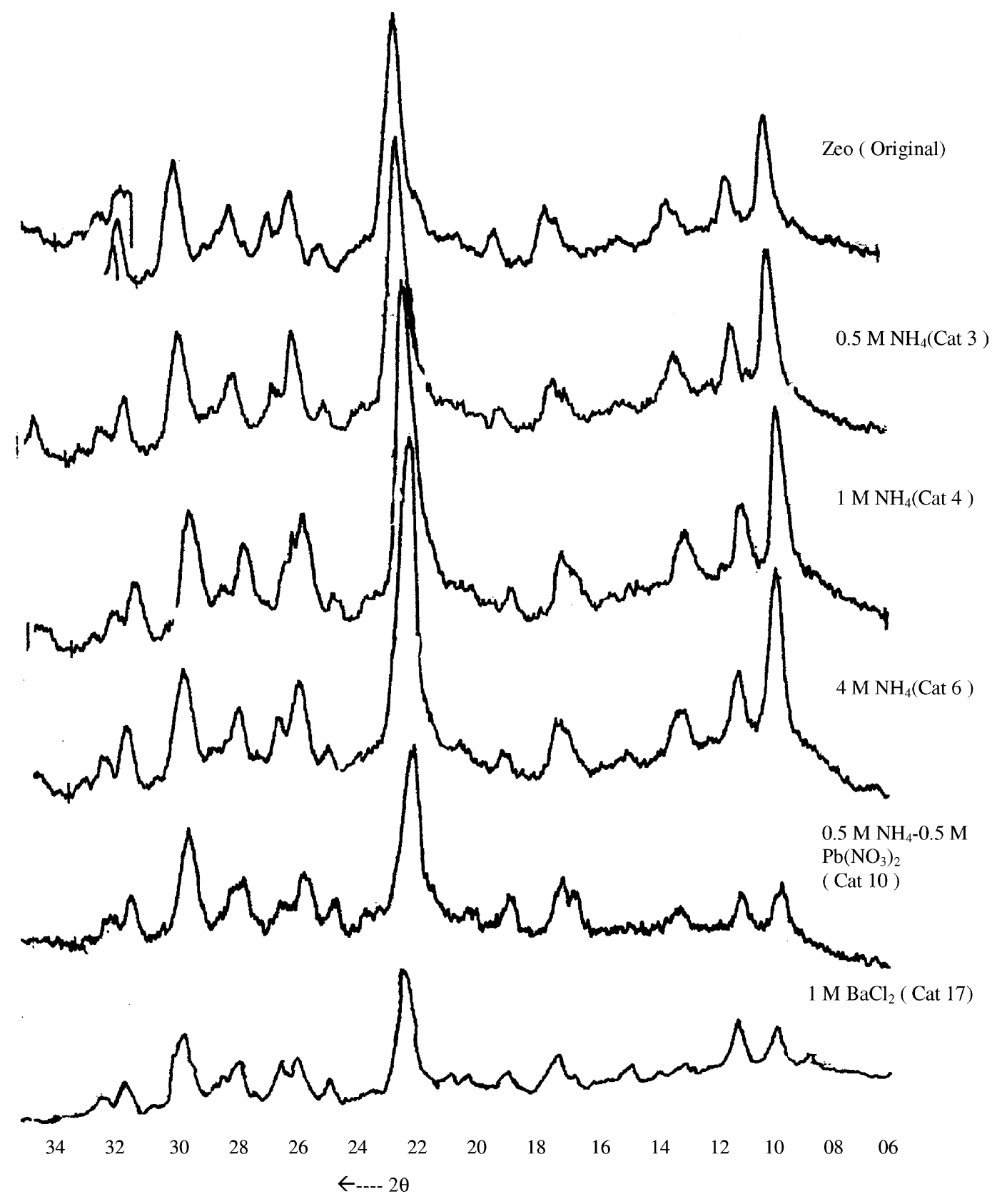

Fig. 15. XRD Patterns of some ion-exchanged zeolites.

ion. This fact permits the differentiation between acid types on the surface of a solid. The density of the sites are evaluated by the intensity (absorbance) of the respective bands, e.g. pyridine bound to Brønsted acid sites is associated with an IR band at $1545 \mathrm{~cm}^{-1}$ and that bound to Lewis sites with a band at $1450 \mathrm{~cm}^{-1}$. A band at $1490 \mathrm{~cm}^{-1}$ arises due to pyridine adsorbed on both Brønsted and Lewis sites [20].

Fig. 16 presents the change in selectivity to camphene and limonene with the relative concentration of Lewis acid sites of several catalyst samples for different reaction durations. Isomerization of $\alpha$-pinene to monocyclic compounds such as limonene is favored on strong (Brønsted) acid sites.
As Lewis sites are weaker than Brønsted sites, camphene and bicyclic products are preferentially formed on the Lewis sites. For low $\mathrm{L} / \mathrm{B}, \alpha$-pinene is preferentially converted on Brønsted sites, yielding monocyclic products. Only when $\mathrm{L} / \mathrm{B}$ is high enough the selectivity to camphene grows significantly $[20,30]$.

Fig. 16a shows a slight increase in the selectivity to camphene and a significant decrease in the selectivity to limonene with increasing L/B ratios of the ion-exchanged zeolites. Fig. 16b shows that selectivity to camphene is not affected by L/B ratio in the range studied. In this figure, selectivity to limonene has not been shown, because 

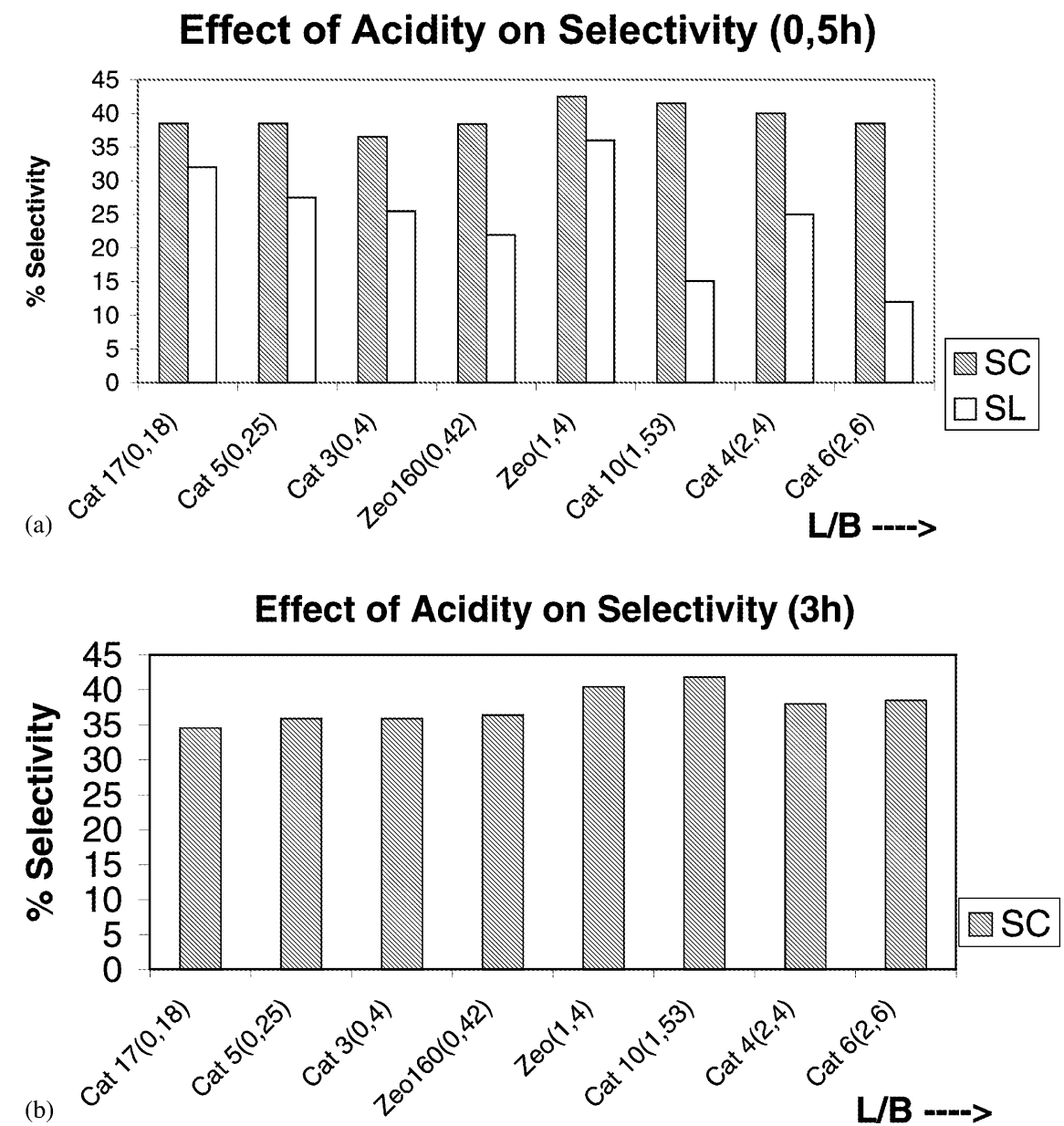

Fig. 16. Selectivity to camphene and limonene as a function of the relative concentrations of Lewis (L) and Brønsted (B) acid sites of several catalysts: (a) $0.5 \mathrm{~h}$ reaction time; (b) $3 \mathrm{~h}$ reaction time.

considerable high amounts of limonene have been consumed for the secondary reactions after a reaction time of $3 \mathrm{~h}$. This is clearly seen from Table 1 . Limonene selectivity for $3 \mathrm{~h}$ is much smaller than that for $0.5 \mathrm{~h}$ for all the catalysts studied.

The behavior over the natural zeolite (Cat. 1) should be treated separately, because acidity effects appear to be more important in a natural zeolite without ion exchange. High selectivities to camphene and limonene are likely to be due to the high enough values Lewis and Brønsted acidities. Selectivity to limonene drops drastically when natural zeolite is heated at $160^{\circ} \mathrm{C}$ for $24 \mathrm{~h}$ (Zeo. 160), due to the loss of a portion of acid sites, a rather low L/B ratio of 0.42 , during dehydration, as seen in Table 1 and Fig. 16, clearly.

The cations exchanged with a zeolite are in different sizes, as demonstrated in DSC studies. Cation exchange with a zeolite may occur at different sites depending on the concentrations and types of cations in the ion-exchange solutions. This causes changes the irregular in L/B ratio. Complicated structure of natural zeolites used as catalyst contributes this irregularity, as well. On the other hand it is expected that the amount of Brønsted sites on the framework increases with increasing $\mathrm{NH}_{4}$ exchange. This cause monocyclic products such as limonene. But as seen from IR spectra, $\mathrm{NH}_{4}$ deformation peak is still present although with decreased intensity, which shows that $\mathrm{NH}_{4}$ zeolite could not be transferred into $\mathrm{H}^{+}$zeolite form at the completion of the thermal treatment. That is why, expected decrease in $\mathrm{L} / \mathrm{B}$ ratio with increasing $\mathrm{NH}_{4}{ }^{+}$concentration is not observed in Fig. 16. It should be kept in mind that IR band at $1490 \mathrm{~cm}^{-1}$ is a measure of both Brønsted and Lewis sites. The contribution of this band on the acidity (Lewis or Brønsted) should be taken into consideration in the explanation of the deviations observed between L/B ratio and selectivities to camphene and limonene.

\section{Conclusions}

Isomerization of $\alpha$-pinene was studied atmospheric pressure under nitrogen flow over catalysts prepared by ion exchange of clinoptilolite-based natural zeolite tuffs with $\mathrm{NH}_{4}{ }^{+}, \mathrm{Ba}^{+}$and $\mathrm{Pb}^{2+}$. Catalysts were characterized with $\mathrm{N}_{2}$ adsorption isotherms, IR, pyridine adsorption, DSC and XRD. 
Activity of catalysts increases with increasing concentration of $\mathrm{NH}_{4}{ }^{+}$solution, $\mathrm{Pb}$ - and Ba-rich zeolites also displayed high reaction rate, mixing of $\mathrm{PbO}$ with a natural zeolite mechanically decreased catalytic activity, while mechanical mixing with $\mathrm{BaO}$ did not cause any rate decrease. However, the results on mechanical mixing with $\mathrm{BaO}$ and $\mathrm{PbO}$ with natural zeolite are the preliminary ones and need further investigation. A first-order dependency on $\alpha$-pinene consumption was observed on the $\mathrm{NH}_{4}{ }^{+}$-exchanged zeolite catalysts.

Two main groups of product were formed: bi- and tricyclic products (camphene and tricyclene) and monoterpenes. Selectivity to bi- and tricyclic products was almost independent on conversion. At high conversions of monoterpene limonene isomerizes to other terpines.

Untreated natural zeolite gave high selectivity to limonene mainly due to the fact that secondary reactions of limonene proceed slower on this catalyst. Modification of zeolites with different ions increased the rates of secondary transformations of limonene. Camphene and bicyclic products were preferentially formed on the Lewis sites while monocyclic products were preferentially formed on the framework Brønsted sites. Acidity effects appeared to be more dominant in untreated natural zeolite. Cation exchange with zeolite may occur at different sites for different ions at different concentrations, causing irregular changes in the ratio of Lewis/Brønsted sites, which affects the product distribution.

\section{Acknowledgements}

Funding for this work from Turkish Scientific Research Council through Grant MISAG-120 and from Ege University Research Fund through Grant 98 Muh 030 is gratefully acknowledged.

\section{References}

[1] S.V. Korotov, V.A. Vyrodov, E.V. Manas'eva, A.I. Kolesov, Z.L. Maslakova, T.D. Oblivantseva, P.K. Cheirkov, P.I. Zhurovlev, O.I. Minaeva, USSR Patent 238,541 (1969).

[2] E.V. Afanas'eva, V.A. Vyrodov, S.V. Korotov, Nauchn. Trudy 135 (1970) 11.

[3] E.V. Afanas'eva, V.A. Vyrodov, S.V. Korotov, Nauchn. Trudy 135 (1970) 20.
[4] Y.Matsubara, Y. Butani, S. Wakabayashi, Y. Watanabe, A. Takamatsu, M. Morita, Japan Patent 28,575 (1970).

[5] A.A. Popov, V.A. Vyrodov, Lesokhim. Prom. 6 (1979) 18.

[6] S.B. Battolova, T.I. Mukltanova, K.G. Tabenova, Vestn. Akad. Nauk. Kaz. SSR 10 (1990) 52.

[7] S. Kullaj, Bull. Shkoncave Nat. 39 (1985) 47.

[8] S. Kullaj, Bull. Shkoncave Nat. 43 (1989) 81.

[9] M. Nazir, M. Ahmed, F.M. Chaudhary, Pak. J. Sci. Ind. Res. 19 (1976) 175.

[10] W.F. Carson, US Patent 2,382,397 (1945).

[11] W.J. Kirkpatrick, US Patent 2,385,711 (1945).

[12] S. Findik, G. Gündüz, JAOCS 74 (1997) 1145.

[13] A. Allahverdiev, G. Gündüz, D.Yu. Murzin, Ind. Eng. Chem. Res. 37 (1998) 2373.

[14] A. Allahverdiev, N.A. Sokolova, G. Gündüz, N.V. Kulkova, Russ. J. Phys. Chem. 72 (1998) 1647.

[15] A. Allahverdiev, S. Irandoust, B. Anderson, D.Yu. Murzin, Appl. Catal. A: Gen. 198 (2000) 197.

[16] O. Akpolat, G. Gündüz, in: L. Petrov, Ch. Bonev, G. Kadinov (Eds.), Heterogeneous Catalysis, Varna, Bulgaria, 2000, p. 331.

[17] C.B. Davis, J.J. McBride, US Patent 3,824,135 (1974).

[18] C.M. López, F.J. Machado, K. Rodriguez, B. Móndez, M. Hasegawa, S. Pekerar, Appl. Catal. A: Gen. 173 (1998) 75.

[19] C.M. López, F.J. Machado, K. Rodriguez, D. Arias, M. Hasegawa, in: A. Corma, F.V. Melo, S. Mendioroz, J.L.G. Fiero (Eds.), Studies in Surface Science and Catalysis, Vol. 130D, Elsevier, Amsterdam, 2000 , p. 3453.

[20] A. Severino, A. Esculcas, J. Rocha, J. Vital, L.S. Lobo, Appl. Catal. A: Gen. 142 (1996) 255.

[21] T. Yamamoto, T. Matsuyama, T. Tanaka, T. Funabaki, S. Yoshida, Phys. Chem. Chem. Phys. 1 (1999) 2841.

[22] T. Yamamoto, T. Tanaka, T. Funabaki, S. Yoshida, J. Phys. Chem. B 102 (1998) 5830.

[23] A.D. Stefanis, G. Perez, A.A.G. Tomlinson, Appl. Catal. A: Gen. 132 (1995) 353.

[24] A.I. Allahverdiev, S. Irandoust, D.Y. Murzin, J. Catal. 185 (1999) 352.

[25] H. Bremer, K.P. Wendlant, Heteregone Katalyse, Akademie-Verlag, New York, 1978.

[26] V.G. Tsitsishvili, G.T. Androniakashvili, N.G. Kirov, D.L. Filizova, Natural Zeolites, Ellis Horwood, New York, 1992.

[27] G.A. Rudakov, L.S. Ivanova, T.N. Pisareva, A.G. Borovskaya, Lesokhim. Gidroliz. Prom. 4 (1975) 7.

[28] S. Brunauer, The Adsorption of Gases and Vapours, Princeton University Press, Princeton, 1943.

[29] M.M. Dubinin, V.A. Astakhov, Izv. Akad. Nauk. SSSR. Ser. Khim. 1971 (1971) 5.

[30] J.J. Gregg, K.J.W. Sing, Adsorption, Surface Area and Porosity, Academic Press, New York, 1982, p. 197.

[31] G.D. Knowlton, T.T. White, H.L. McKague, Thermal study of types of water associated with clinoptilolite, Clays Clay Miner. 29 (1981) 403-411. 